\title{
Total Synthesis of LFA-1 Antagonist BIRT-377 via Organocatalytic Asymmetric Construction of a Quaternary Stereocenter
}

\author{
Naidu S. Chowdari and Carlos F. Barbas III* \\ Contribution from The Skaggs Institute for Chemical Biology and the Departments of Chemistry and Molecular \\ Biology, The Scripps Research Institute, 10550 North Torrey Pines Road, La Jolla, California
}

Supporting Information

General. Chemicals and solvents were either purchased puriss p.A. from commercial suppliers or purified by standard techniques. For thin-layer chromatography (TLC), silica gel plates Merck 60 F254 were used and compounds were visualized by irradiation with UV light and/or by treatment with a solution of $p$-anisaldehyde $(23 \mathrm{~mL})$, conc. $\mathrm{H}_{\mathbf{L}} \mathrm{SO}_{4}(35 \mathrm{~mL})$, acetic acid (10 $\mathrm{mL}$ ), and ethanol $(900 \mathrm{~mL})$ followed by heating. Flash chromatography was performed using silica gel Merck 60 (particle size 0.040-0.063 mm), ${ }^{1} \mathrm{H}$ NMR and ${ }^{13} \mathrm{C}$ NMR spectra were recorded on Bruker DRX-400, DRX-600 MHz. Chemical shifts are given in $\delta$ relative to tetramethylsilane (TMS), the coupling constants $J$ are given in $\mathrm{Hz}$. The spectra were recorded in $\mathrm{CDCl}_{3}$ as solvent at room temperature, TMS served as internal standard $(\delta=0 \mathrm{ppm})$ for ${ }^{1} \mathrm{H}$ $\mathrm{NMR}$, and $\mathrm{CDCl}_{3}$ was used as internal standard $(\delta=77.0 \mathrm{ppm})$ for ${ }^{13} \mathrm{C}$ NMR. HPLC was carried out using a Hitachi organizer consisting of a D-2500 Chromato-Integrator, a L-4000 UVDetector, and a L-6200A Intelligent Pump. Optical rotations were recorded on a Perkin Elemer 241 Polarimeter $(\lambda=589 \mathrm{~nm}, 1 \mathrm{dm}$ cell). High-resolution mass spectra were recorded on an IonSpec FTMS mass spectrometer with a DHB-matrix.

(E)-3-(4-bromophenyl)-2-methylacrylaldehyde (5): Method A. To a solution of dimethylammonium dimethyl carbamate (DIMCARB) $(3 \mathrm{~mL})$ and 4-bromobenzaldehyde (1.74 $\mathrm{g}, 9.4 \mathrm{mmol})$ in round-bottom flask was added propionaldehyde $(1.36 \mathrm{~mL}, 18.6 \mathrm{mmol})$ and stirred at room temperature for $48 \mathrm{~h}$. Then, DIMCARB was removed by distillation and the residue was diluted with $0.5 \mathrm{M} \mathrm{H}_{2} \mathrm{SO}_{4}$. The aqueous layer was extracted with $\mathrm{CH}_{2} \mathrm{Cl}_{2}$ and the combined organic phases were dried $\left(\mathrm{Na}_{2} \mathrm{SO}_{4}\right)$, concentrated, and purified by flash column 
chromatography (silica gel, hexanes/ethyl acetate $=95: 5)$ to afford the desired product 5 (1.692 g, 80\% yield). ${ }^{1} \mathrm{H}$ NMR $\left(\mathrm{CDCl}_{3}, 400 \mathrm{MHz}\right): \delta 2.05$ (d, $\left.J=0.9 \mathrm{~Hz}, 3 \mathrm{H}\right), 7.20(\mathrm{~s}, 1 \mathrm{H}), 7.39(\mathrm{~d}, J=$ $8.5 \mathrm{~Hz}, 2 \mathrm{H}), 7.58(\mathrm{~d}, J=8.2 \mathrm{~Hz}, 2 \mathrm{H}), 9.58(\mathrm{~s}, 1 \mathrm{H})$.

Method B: To a cooled stirring solution of 4-bromobenzaldehyde (18.5 g, $0.1 \mathrm{~mol})$ in $\mathrm{MeOH}$ (20 mL) 10\% aqueous $\mathrm{NaOH}(4 \mathrm{~mL})$ was added followed by slow addition of propionaldehyde $(5.6 \mathrm{~mL}, 0.12 \mathrm{~mol})$ over $3 \mathrm{~h}$ at room temperature. Then reaction mixture was stirred for an additional $2 \mathrm{~h}$ and cooled to $0{ }^{\circ} \mathrm{C}$ and quenched with $1 \mathrm{~N} \mathrm{HCl}(15 \mathrm{~mL})$. The precipitated solid was filtered and purified by flash column chromatography (silica gel, hexanes/ethyl acetate = 95:5) to afford the desired product 5 (17.55 g, 78\% yield).

3-(4-bromophenyl)-2-methylpropan-1-ol (6): To a three neck round-bottom flask with $\mathrm{LiAlH}_{4}$ (101.7 mmol, $1 \mathrm{M}$ ether solution) at $0{ }^{\circ} \mathrm{C}$ under $\mathrm{N}_{2}$ was added aldehyde 5 (14.575 g, $\left.64.78 \mathrm{mmol}\right)$ in THF $(300 \mathrm{~mL})$ followed by $\mathrm{AlCl}_{3}(34.98 \mathrm{mmol})$. The reaction temperature was increased to $65{ }^{\circ} \mathrm{C}$ and stirred for $11 \mathrm{~h}$. The reaction was cooled to $0{ }^{\circ} \mathrm{C}$ and quenched with $2 \mathrm{~N} \mathrm{HCl}(270$ $\mathrm{mL})$. Two layers are separated. The aqueous layer was extracted with EtOAc $(2 \mathrm{x} 100 \mathrm{~mL})$. The combined organic phases were dried $\left(\mathrm{Na}_{2} \mathrm{SO}_{4}\right)$, concentrated, and purified by flash column chromatography (silica gel, hexanes/ethyl acetate $=70: 30$ ) to afford the desired product 6 (12.609 g, 85\% yield). ${ }^{1} \mathrm{H} \mathrm{NMR}\left(\mathrm{CDCl}_{3}, 400 \mathrm{MHz}\right): \delta 0.90(\mathrm{~d}, J=8.0 \mathrm{~Hz}, 3 \mathrm{H}), 1.91(\mathrm{~m}, 1 \mathrm{H})$, $2.38(\mathrm{dd}, J=12.0,8.0 \mathrm{~Hz}, 1 \mathrm{H}), 2.74(\mathrm{dd}, J=12.0,8.0 \mathrm{~Hz}, 1 \mathrm{H}), 3.50(\mathrm{~d}, J=4.0 \mathrm{~Hz}, 1 \mathrm{H}), 7.05$ $(\mathrm{d}, J=8.0 \mathrm{~Hz}, 2 \mathrm{H}), 7.40(\mathrm{~d}, J=8.0 \mathrm{~Hz}, 2 \mathrm{H})$.

3-(4-bromophenyl)-2-methylpropanal (4): To a three neck round-bottom flask with oxalyl chloride $(5.475 \mathrm{~mL}, 60.34 \mathrm{mmol})$ in $\mathrm{CH}_{2} \mathrm{Cl}_{2}(125 \mathrm{~mL})$ at $-60{ }^{\circ} \mathrm{C}$ under $\mathrm{N}_{2}$ was added DMSO (9.308 mL, $120.68 \mathrm{mmol})$ in $\mathrm{CH}_{2} \mathrm{Cl}_{2}$ (66 mL) followed by alcohol 6 (12.562 g, $\left.54.85 \mathrm{mmol}\right)$ in $\mathrm{CH}_{2} \mathrm{Cl}_{2}(55 \mathrm{~mL})$ and stirred for $30 \mathrm{~min} . \mathrm{Et}_{3} \mathrm{~N}(38.38 \mathrm{~mL}, 274.27 \mathrm{mmol})$ was added and the reaction mixture was stirred for $5 \mathrm{~min}$ and then allowed to warm to room temperature. The combined organic phases were washed with water and dried $\left(\mathrm{Na}_{2} \mathrm{SO}_{4}\right)$, concentrated, and purified by flash column chromatography (silica gel, hexanes/ethyl acetate $=95: 5$ ) to afford the desired product 4 (11.828 g, 95\% yield). ${ }^{1} \mathrm{H}$ NMR $\left(\mathrm{CDCl}_{3}, 400 \mathrm{MHz}\right): \delta 1.09$ (d, $J=7.0 \mathrm{~Hz}$, 3H), $2.55(\mathrm{dd}, J=13.5,8.2 \mathrm{~Hz}, 1 \mathrm{H}), 2.63(\mathrm{~m}, 1 \mathrm{H}), 3.04(\mathrm{dd}, J=13.5,5.9 \mathrm{~Hz}, 1 \mathrm{H}), 7.04(\mathrm{~d}, J=$ 
$8.2 \mathrm{~Hz}, 2 \mathrm{H}), 7.41(\mathrm{~d}, J=8.5 \mathrm{~Hz}, 2 \mathrm{H}), 9.70(\mathrm{~d}, J=1.5 \mathrm{~Hz}, 1 \mathrm{H}) ;{ }^{13} \mathrm{C} \mathrm{NMR}\left(\mathrm{CDCl}_{3}, 100 \mathrm{MHz}\right) \delta$ $13.2,35.9,47.9,120.3,130.8,131.6,137.9,203.9$.

(R)-3-(4-bromophenyl)-2-(1,2-benzyloxycarbonylhydrazinyl)-2-methylpropanal $\quad(3): \quad$ To a glass vial charged with (S)-5-(pyrrolidin-2-yl)-1H-tetrazole (104 mg, $0.75 \mathrm{mmol}$ ) was added $\mathrm{CH}_{3} \mathrm{CN}(10 \mathrm{~mL})$ followed by bis dibenzyl azodicarboxylate $(1.59 \mathrm{~g}, 5 \mathrm{mmol})$, aldehyde 4 (1.703 $\mathrm{g}, 7.5 \mathrm{mmol}$ ) and the reaction was stirred at room temperature until completion as monitored by TLC $(3 \mathrm{~h})$. Then, a half saturated $\mathrm{NH}_{4} \mathrm{Cl}$ solution and ethyl acetate were added with vigorous stirring, the layers were separated and the organic phase was washed with water. The combined organic phases were dried $\left(\mathrm{Na}_{2} \mathrm{SO}_{4}\right)$, concentrated, and purified by flash column chromatography (silica gel, hexanes/ethyl acetate $=70: 30)$ to afford the desired product 3 (2.489 g, 95\% yield). Recrystallization from hexanes/ethyl acetate (70:30) furnished the mother liquor with $>99 \%$ ee $(71 \%$ yield $) .[\alpha]^{25}=82.0\left(\mathrm{c}=1.0, \mathrm{CHCl}_{3}\right)$; NMR spectrum exists as a mixture of rotamers at room temperature $\left(\mathrm{CDCl}_{3}, 600 \mathrm{MHz}, 50{ }^{\circ} \mathrm{C}\right): \delta 1.15(\mathrm{~s}, 3 \mathrm{H}), 2.83(\mathrm{bs}, 1 \mathrm{H}), 3.28(\mathrm{bs}$, $1 \mathrm{H}), 5.04-5.21(\mathrm{~m}, 4 \mathrm{H}), 6.76(\mathrm{bs}, 2 \mathrm{H}), 7.31(\mathrm{~m}, 12 \mathrm{H}), 9.67(\mathrm{bs}, 1 \mathrm{H}) ;{ }^{13} \mathrm{C} \mathrm{NMR}\left(\mathrm{CDCl}_{3}, 150\right.$ $\left.\mathrm{MHz}, 50{ }^{\circ} \mathrm{C}\right) \delta 18.28,37.41,68.18,70.27,128.20,128.47,128.54,128.58,128.64,131.78$, 131.86, 135.32, 150.25, 155.58, 193.30; HRMS for $\mathrm{C}_{26} \mathrm{H}_{26} \mathrm{BrN}_{2} \mathrm{O} 5\left(\mathrm{MH}^{+}\right)$: calcd 525.1027, obsd 525.1018; HPLC (Daicel Chirapak AS-H, hexane/isopropanol = $90: 10$, flow rate $1.0 \mathrm{~mL} / \mathrm{min}$, $\lambda=254 \mathrm{~nm}): \mathrm{t}_{\mathrm{R}}=26.14 \min ($ major $), \mathrm{t}_{\mathrm{R}}=33.36 \mathrm{~min}$ (minor).

\section{(R)-3-(4-bromophenyl)-2-(1,2- benzyloxycarbonylhydrazinyl)-2-methylpropanoic acid (7):}

To a solution of amino aldehyde $3(695 \mathrm{mg}, 1.326 \mathrm{mmol})$ in $t-\mathrm{BuOH}-\mathrm{H}_{2} \mathrm{O}(5: 1,14 \mathrm{~mL})$ at $4{ }^{\circ} \mathrm{C}$ $\mathrm{NaClO}_{2}(5.30 \mathrm{mmol}), \mathrm{NaH}_{2} \mathrm{PO}_{4}(318 \mathrm{mg}, 2.65 \mathrm{mmol})$ and 2-methtl-2-butene $(5.3 \mathrm{~mL}$ of $2 \mathrm{M}$ THF solution, $10.61 \mathrm{mmol}$ ) was added and stirred for $12 \mathrm{~h}$. After completion of the reaction as monitored by TLC the solvent was removed under vacuum. The crude material was extracted with ethyl acetate and washed with brine and water. The combined organic phases were dried $\left(\mathrm{Na}_{2} \mathrm{SO}_{4}\right)$, concentrated, and purified by flash column chromatography (silica gel, methanol/ethyl acetate $=5: 95)$ to afford the corresponding acid 7 as a white solid $(616 \mathrm{mg}, 86 \%$ yield). $[\alpha]_{\mathrm{D}}^{25}=10.2(\mathrm{c}=0.5, \mathrm{MeOH}) ;{ }^{1} \mathrm{H} \mathrm{NMR}\left(\mathrm{CD}_{3} \mathrm{OD}, 600 \mathrm{MHz}, 50{ }^{\circ} \mathrm{C}\right): \delta 1.71(\mathrm{~s}, 3 \mathrm{H}), 3.37$ $(\mathrm{d}, J=13.2 \mathrm{~Hz}, 1 \mathrm{H}), 3.55$ (bs, 1H), $5.40-5.48(\mathrm{~m}, 5 \mathrm{H}), 7.29$ (d, J = 7.8 Hz, 2H), $7.61(\mathrm{~m}, 10 \mathrm{H})$, 
$7.66(\mathrm{~d}, J=7.8 \mathrm{~Hz}, 2 \mathrm{H}) ;{ }^{13} \mathrm{C}$ NMR $\left(\mathrm{CD}_{3} \mathrm{OD}, 150 \mathrm{MHz}, 50{ }^{\circ} \mathrm{C}\right) \delta 21.35,28.61,69.17,68.47$, 69.42, 121.99, 129.10, 129.36, 129.56, 131.93, 132.39, 133.59, 134.12, 136.43, 137.32, 156.59, 175.78; HRMS for $\mathrm{C}_{26} \mathrm{H}_{25} \mathrm{BrN}_{2} \mathrm{O}_{6} \mathrm{Na}\left(\mathrm{MNa}^{+}\right)$: calcd 563.0788, obsd 563.0788.

(R)-Methyl 3-(4-bromophenyl)-2-(1,2- benzyloxycarbonylhydrazinyl)-2-methylpropanoate (8): To a solution of amino acid $7(471 \mathrm{mg}, 0.872 \mathrm{mmol})$ in toluene-MeOH $(2: 1,20 \mathrm{~mL})$ (trimethylsilyl)diazomethane $(0.872 \mathrm{~mL}$ of $2 \mathrm{M}$ solution in hexanes, $1.744 \mathrm{mmol})$ was added and stirred at room temperature for $10 \mathrm{~min}$. Then the excess of trimethyl silyl diazomethane was quenched by drop wise addition of acetic acid. The solvent was removed under vacuum and the residue was purified by flash column chromatography (silica gel, hexanes/ethyl acetate $=70: 30$ ) to afford the desired product 8 (478 mg, 99\% yield). $[\alpha]^{25} \mathrm{D}=42.8\left(\mathrm{c}=1, \mathrm{CHCl}_{3}\right) ;{ }^{1} \mathrm{H} \mathrm{NMR}$ $\left(\mathrm{CDCl}_{3}, 600 \mathrm{MHz}, 50{ }^{\circ} \mathrm{C}\right): \delta 1.40$ (s, 3H), 2.97 (bs, $\left.1 \mathrm{H}\right), 3.26$ (bs, $\left.1 \mathrm{H}\right), 3.57$ (s, 3H), $5.06-5.16$ (m, 4H), 6.83 (bs, 1H), 7.29 (m, 14H); ${ }^{13} \mathrm{C}$ NMR $\left(\mathrm{CDCl}_{3}, 150 \mathrm{MHz}, 50{ }^{\circ} \mathrm{C}\right) \delta 21.06,41.21$, 52.24, 67.94, 68.40, 107.95, 128.29, 128.12, 128.36, 128.54, 131.69, 131.95, 134.98, 135.65, 154.95, 156.19, 173.04; HRMS for $\mathrm{C}_{27} \mathrm{H}_{27} \mathrm{BrN}_{2} \mathrm{O}_{6} \mathrm{Na}\left(\mathrm{MNa}^{+}\right)$: calcd 577.0945, obsd 577.0941.

\section{(R)-Methyl}

3-(4-bromophenyl)-2-methyl-2-(1-benzyloxycarbonyl-2-(2,2,2trifluoroacetyl)hydrazinyl)propanoate (9): A solution of amino acid ester 8 (453 $\mathrm{mg}, 0.817$ mmol) in pyridine $(2 \mathrm{~mL})$ was heated at $40{ }^{\circ} \mathrm{C}$ for $18 \mathrm{~h}$. Then the reaction was cooled to $0{ }^{\circ} \mathrm{C}$ and trifluoroacetic anhydride $(0.596 \mathrm{~mL}, 4.29 \mathrm{mmol})$ was added and stirred at room temperature for $48 \mathrm{~h}$. The volatiles were removed under vacuum and the residue was purified by flash column chromatography (silica gel, hexanes/ethyl acetate $=70: 30$ ) to afford the desired product 9 (417 mg, 99\% yield). $[\alpha]^{25} \mathrm{D}=14.3\left(\mathrm{c}=1, \mathrm{CHCl}_{3}\right) ;{ }^{1} \mathrm{H}$ NMR $\left(\mathrm{CDCl}_{3}, 600 \mathrm{MHz}, 50\right.$ $\left.{ }^{\circ} \mathrm{C}\right): \delta 1.43(\mathrm{~s}, 3 \mathrm{H}), 3.12(\mathrm{bs}, 1 \mathrm{H}), 3.37(\mathrm{bs}, 1 \mathrm{H}), 3.64(\mathrm{~s}, 3 \mathrm{H}), 5.13(\mathrm{~d}, J=12.0 \mathrm{~Hz}, 1 \mathrm{H}), 5.22(\mathrm{~d}$, $J=12.0 \mathrm{~Hz}, 1 \mathrm{H}), 6.94$ (bs, 2H), $7.30-7.37$ (m, 7H); ${ }^{13} \mathrm{C} \mathrm{NMR}\left(\mathrm{CDCl}_{3}, 150 \mathrm{MHz}, 50{ }^{\circ} \mathrm{C}\right) \delta$ 21.24, 41.08, 52.66, 67.83, 69.08, 114.59, 116.51, 121.60, 128.33, 128.67, 128.71, 131.66, 132.20, 134.29, 135.09, 156.60, 156.85, 172.92; HRMS for $\mathrm{C}_{21} \mathrm{H}_{20} \mathrm{BrF}_{3} \mathrm{~N}_{2} \mathrm{O}_{5} \mathrm{Na}\left(\mathrm{MNa}^{+}\right)$: calcd 539.0408, obsd 539.0405. 
$\begin{array}{lllll}\text { (R)-Methyl 2-(benzyloxycarbonyl)-3-(4-bromophenyl)-2-methylpropanoate } & \text { (2): } \quad \text { To a }\end{array}$ solution of amino acid ester 9 (361 mg, $0.7 \mathrm{mmol})$ in $\mathrm{MeOH}(1.4 \mathrm{~mL}) 0.1 \mathrm{M}$ solution of samarium iodide in THF $(47.5 \mathrm{~mL})$ was added under $\mathrm{N}_{2}$ and stirred at room temperature for 30 min. The volatiles were removed under vacuum and the residue was purified by flash column chromatography (silica gel, hexanes/ethyl acetate $=70: 30$ ) to afford the desired product 2 (278 mg, 98\% yield). $[\alpha]^{25}{ }_{\mathrm{D}}=-44.1\left(\mathrm{c}=1, \mathrm{CHCl}_{3}\right) ;{ }^{1} \mathrm{H} \mathrm{NMR}\left(\mathrm{CDCl}_{3}, 600 \mathrm{MHz}, 50{ }^{\circ} \mathrm{C}\right): \delta 1.61(\mathrm{~s}$, 3H), $3.13(\mathrm{~d}, J=13.8 \mathrm{~Hz}, 1 \mathrm{H}), 3.38(\mathrm{~d}, J=13.8 \mathrm{~Hz}, 1 \mathrm{H}), 3.72(\mathrm{~s}, 3 \mathrm{H}), 5.07$ (d, $J=12.6 \mathrm{~Hz}$, $1 \mathrm{H}), 5.15(\mathrm{~d}, J=12.6 \mathrm{~Hz}, 1 \mathrm{H}), 5.38(\mathrm{bs}, 1 \mathrm{H}), 6.83(\mathrm{~d}, J=7.8 \mathrm{~Hz}, 2 \mathrm{H}), 7.28(\mathrm{~d}, J=8.4 \mathrm{~Hz}, 2 \mathrm{H})$, $7.35(\mathrm{~m}, 5 \mathrm{H}) ;{ }^{13} \mathrm{C} \mathrm{NMR}\left(\mathrm{CDCl}_{3}, 125 \mathrm{MHz}, 50{ }^{\circ} \mathrm{C}\right) \delta 23.80,41.11,52.59,60.78,66.53,121.02$, $128.20,128.52,131.36,131.55,135.25,136.66,154.62,173.78$; HRMS for $\mathrm{C}_{1} \mathrm{H}_{20} \mathrm{BrNO}_{4} \mathrm{Na}$ $\left(\mathrm{MNa}^{+}\right)$: calcd 428.0468, obsd 428.0470.

(R)-Methyl 2-amino-3-(4-bromophenyl)-2-methylpropanoate (10): To a solution of amino acid ester 2 (156 mg, $0.385 \mathrm{mmol})$ in $\mathrm{AcOH}(1.0 \mathrm{~mL}) 33 \% \mathrm{HBr}$ in $\mathrm{AcOH}$ solution $(0.7 \mathrm{~mL})$ was added and stirred at room temperature for $24 \mathrm{~h}$. The volatiles were removed under vacuum and the residue was diluted with ethyl acetate and water. The aqueous layer was neutralized with sat aq $\mathrm{NaHCO}_{3}$ solution and extracted with $\mathrm{CH}_{2} \mathrm{Cl}_{2}(3 \times 5 \mathrm{~mL})$. The combined organic phases were dried $\left(\mathrm{Na}_{2} \mathrm{SO}_{4}\right)$ and concentrated to afford the pure product $10(103 \mathrm{mg}, 99 \%$ yield $) .[\alpha]^{25}=$ $17.4\left(\mathrm{c}=1, \mathrm{CHCl}_{3}\right) ;{ }^{1} \mathrm{H}$ NMR $\left(\mathrm{CDCl}_{3}, 400 \mathrm{MHz}\right): \delta 1.39(\mathrm{~s}, 3 \mathrm{H}), 1.80(\mathrm{bs}, 2 \mathrm{H}), 2.77(\mathrm{~d}, J=13.2$ Hz, 1H), $3.08(\mathrm{~d}, J=13.2 \mathrm{~Hz}, 1 \mathrm{H}), 3.70(\mathrm{~s}, 3 \mathrm{H}), 7.03(\mathrm{~d}, J=8.4 \mathrm{~Hz}, 2 \mathrm{H}), 7.41(\mathrm{~d}, J=8.4 \mathrm{~Hz}$, $2 \mathrm{H}) ;{ }^{13} \mathrm{C} \mathrm{NMR}\left(\mathrm{CDCl}_{3}, 100 \mathrm{MHz}\right) \delta 26.43,46.09,52.22,58.78,121.06,131.44,131.64,135.41$, 177.08; HRMS for $\mathrm{C}_{11} \mathrm{H}_{15} \mathrm{BrNO}_{2}\left(\mathrm{MH}^{+}\right)$: calcd 272.0281, obsd 272.0274.

\section{(R)-5-(4-bromobenzyl)-3-(3,5-dichlorophenyl)-5-methylimidazolidine-2,4-dione (11): A}

solution of amine $10(87 \mathrm{mg}, 0.321 \mathrm{mmol})$ and 3,5-dichlorophenyl isocyanate (60 $\mathrm{mg}, 0.321$ $\mathrm{mmol})$ in dry DMSO $(0.6 \mathrm{~mL})$ was stirred at room temperature for $1 \mathrm{~h}$. Then sodium carbonate (68 mg, $0.642 \mathrm{mmol}$ ) was added and stirred at $120{ }^{\circ} \mathrm{C}$ for $12 \mathrm{~h}$. The reaction mixture was brought to room temperature and diluted with ethyl acetate and washed with water and aq $\mathrm{NH}_{4} \mathrm{Cl}$ solution. The organic phase was dried $\left(\mathrm{Na}_{2} \mathrm{SO}_{4}\right)$, concentrated, and purified by flash column chromatography ( silica gel, hexanes/ethyl acetate $=70: 30$ ) to afford the desired product 
$11\left(135 \mathrm{mg}, 99 \%\right.$ yield). $[\alpha]^{25}{ }_{\mathrm{D}}=119.5\left(\mathrm{c}=0.86, \mathrm{CH}_{2} \mathrm{Cl}_{2}\right) ;{ }^{1} \mathrm{H} \mathrm{NMR}\left(\mathrm{CDCl}_{3}, 400 \mathrm{MHz}\right): \delta 1.61$ (s, 3H), 2.92 (d, $J=13.6 \mathrm{~Hz}, 1 \mathrm{H}), 3.14(\mathrm{~d}, J=13.6 \mathrm{~Hz}, 1 \mathrm{H}), 5.84$ (bs, 1H), 7.01 (d, $J=1.6 \mathrm{~Hz}$, 2H), $7.07(\mathrm{~d}, J=8.4 \mathrm{~Hz}, 2 \mathrm{H}), 7.34(\mathrm{t}, J=1.6 \mathrm{~Hz}, 1 \mathrm{H}), 7.46(\mathrm{~d}, J=8.4 \mathrm{~Hz}, 2 \mathrm{H}) ;{ }^{13} \mathrm{C}$ NMR $\left(\mathrm{CDCl}_{3}, 100 \mathrm{MHz}\right) \delta 29.7,43.7,62.5,122.1,124.5,128.5,132.8,131.7,132.7,135.2,154.0$, 174.0; HRMS for $\mathrm{C}_{17} \mathrm{H}_{12} \mathrm{BrCl}_{2} \mathrm{~N}_{2} \mathrm{O}_{2}\left(\mathrm{M}-\mathrm{H}^{+}\right)$: calcd 424.9465, obsd 424.9445 .

(R)-5-(4-bromobenzyl)-3-(3,5-dichlorophenyl)-1,5-dimethylimidazolidine-2,4-dione (1): To a solution of hydantoin $11(118 \mathrm{mg}, 0.2769 \mathrm{mmol})$ in $\mathrm{DMF}(1 \mathrm{~mL})$ at $4{ }^{\circ} \mathrm{C}$ lithium bi(trimethylsilyl)amide $(0.321 \mathrm{mmol}$ of $1 \mathrm{M}$ THF solution) followed by iodomethane ( $26 \mu \mathrm{L}$, $0.415 \mathrm{mmol}$ ) were added and stirred at room temperature for $3 \mathrm{~h}$. The reaction mixture was diluted with water and extracted with ethyl acetate $(3 \times 5 \mathrm{~mL})$. The combined organics were washed with aq $\mathrm{NH}_{4} \mathrm{Cl}$ solution and dried $\left(\mathrm{Na}_{2} \mathrm{SO}_{4}\right)$, concentrated, and purified by flash column chromatography (silica gel, hexanes/ethyl acetate $=70: 30)$ to afford the desired product $\mathbf{1}$ (115 mg, $94 \%$ yield). $[\alpha]^{25}{ }_{\mathrm{D}}=131.6(\mathrm{c}=1.0, \mathrm{EtOH}) ;$ HPLC (Daicel Chirapak AD, hexane $/ \mathrm{EtOH} / \mathrm{Et}_{2} \mathrm{NH}=300: 10: 1$, flow rate $\left.1.0 \mathrm{~mL} / \mathrm{min}, \lambda=254 \mathrm{~nm}\right): \mathrm{t}_{\mathrm{R}}=15.62 \mathrm{~min},(+) 1$ $(\mathrm{BIRT}-377) ; \mathrm{t}_{\mathrm{R}}=17.23 \mathrm{~min}(-) \mathbf{1} ;{ }^{1} \mathrm{H} \mathrm{NMR}\left(\mathrm{CDCl}_{3}, 400 \mathrm{MHz}\right): \delta 1.63(\mathrm{~s}, 3 \mathrm{H}), 2.97(\mathrm{~d}, J=14.0$ $\mathrm{Hz}, 1 \mathrm{H}), 3.08(\mathrm{~s}, 3 \mathrm{H}), 3.10(\mathrm{~d}, J=15.2 \mathrm{~Hz}, 1 \mathrm{H}), 6.84(\mathrm{~d}, J=2.0 \mathrm{~Hz}, 2 \mathrm{H}), 6.94(\mathrm{~d}, J=8.4 \mathrm{~Hz}$, $2 \mathrm{H}), 7.29(\mathrm{t}, J=2.0 \mathrm{~Hz}, 1 \mathrm{H}), 7.42(\mathrm{~d}, J=8.4 \mathrm{~Hz}, 2 \mathrm{H}) ;{ }^{13} \mathrm{C} \mathrm{NMR}\left(\mathrm{CDCl}_{3}, 100 \mathrm{MHz}\right) \delta 21.0$, 25.3, 40.7, 65.6, 121.9, 124.5, 128.3, 131.1, 131.8, 132.8, 133.0, 135.0, 153.4, 173.3; HRMS for $\mathrm{C}_{18} \mathrm{H}_{16} \mathrm{BrCl}_{2} \mathrm{~N}_{2} \mathrm{O}_{2}\left(\mathrm{MH}^{+}\right)$: calcd 440.9767, obsd 440.9759. 


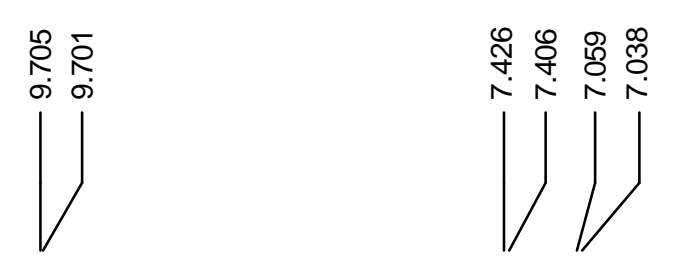

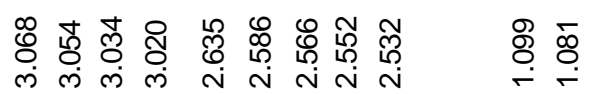
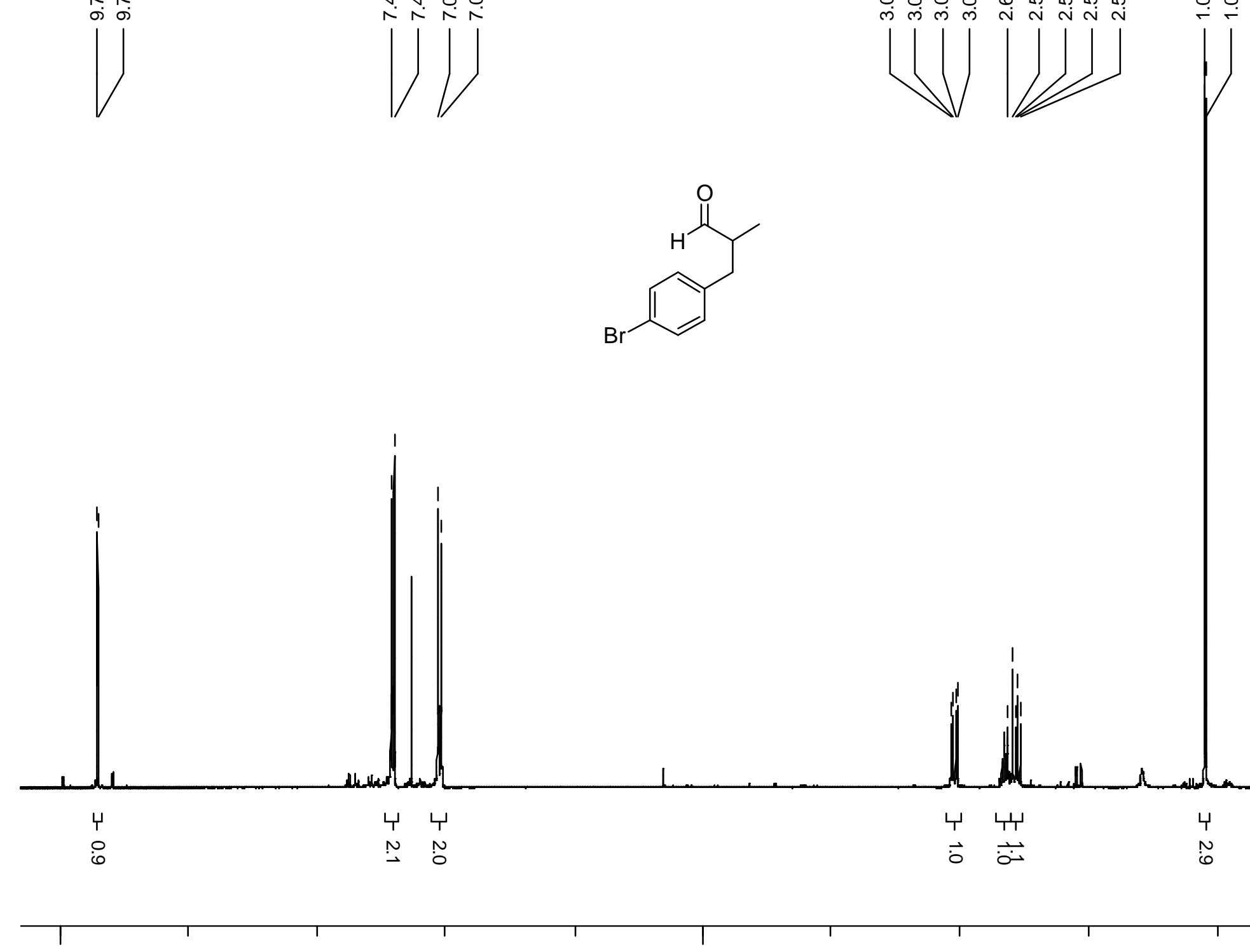

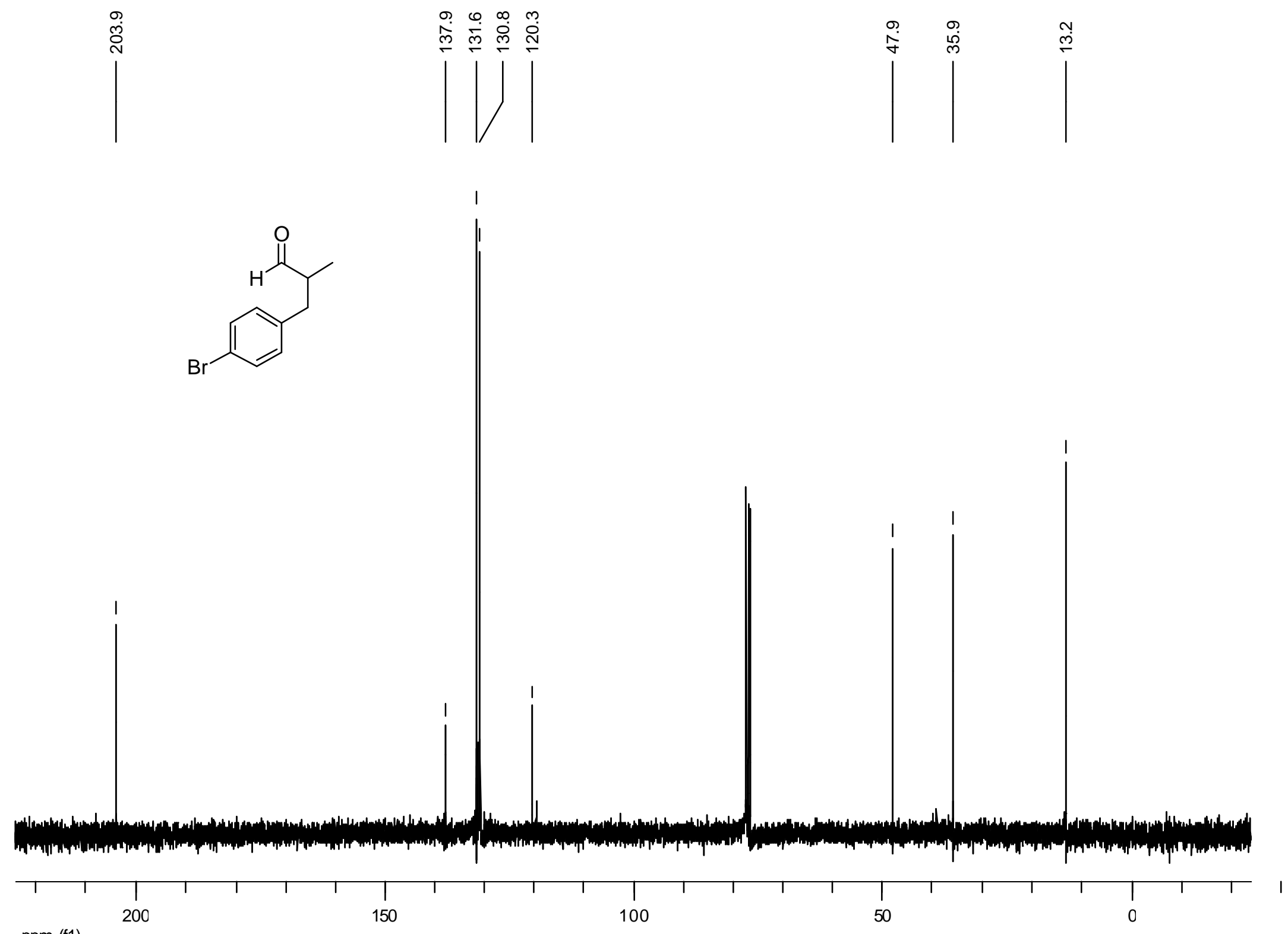

ppm (f1) 

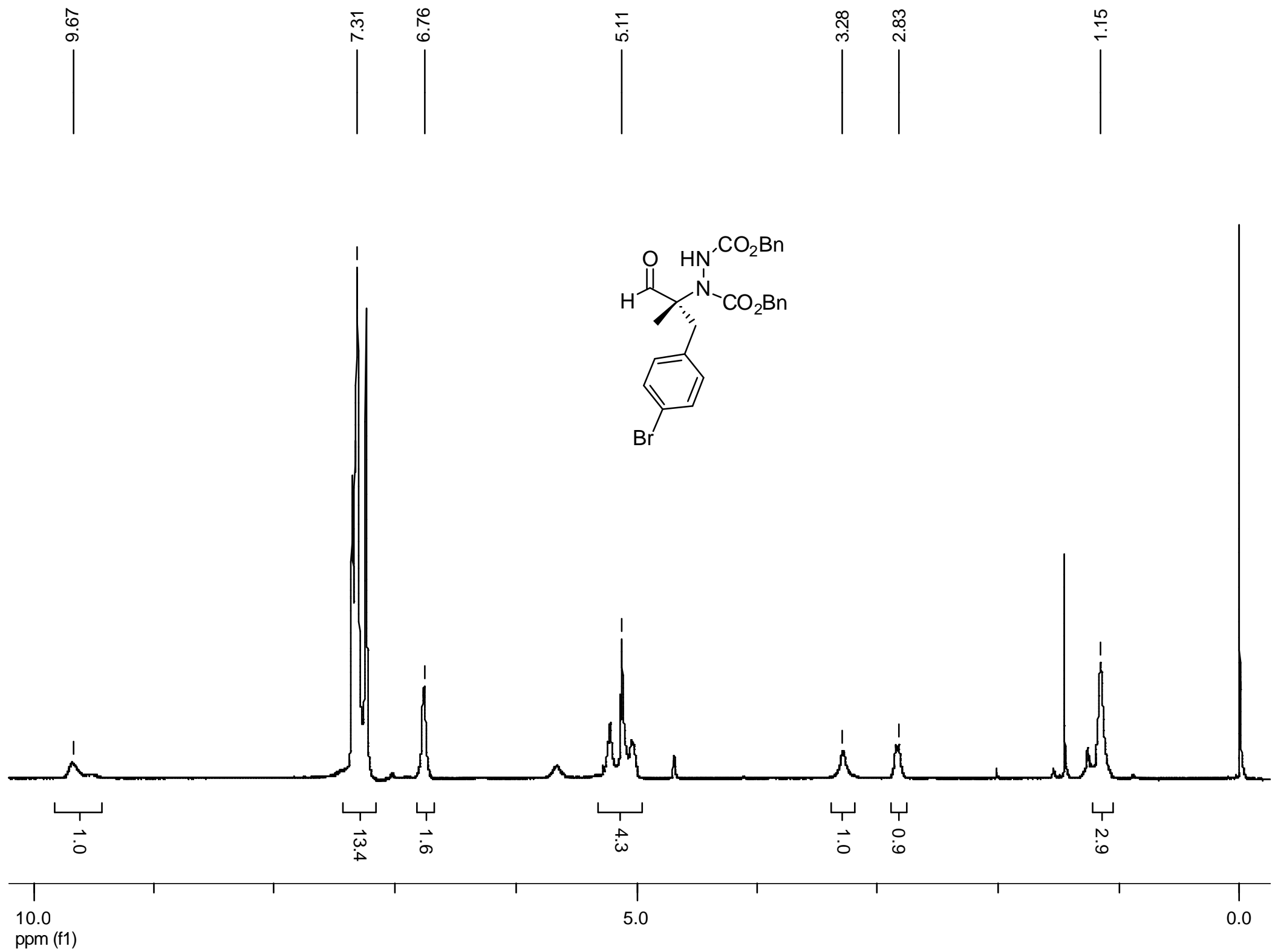


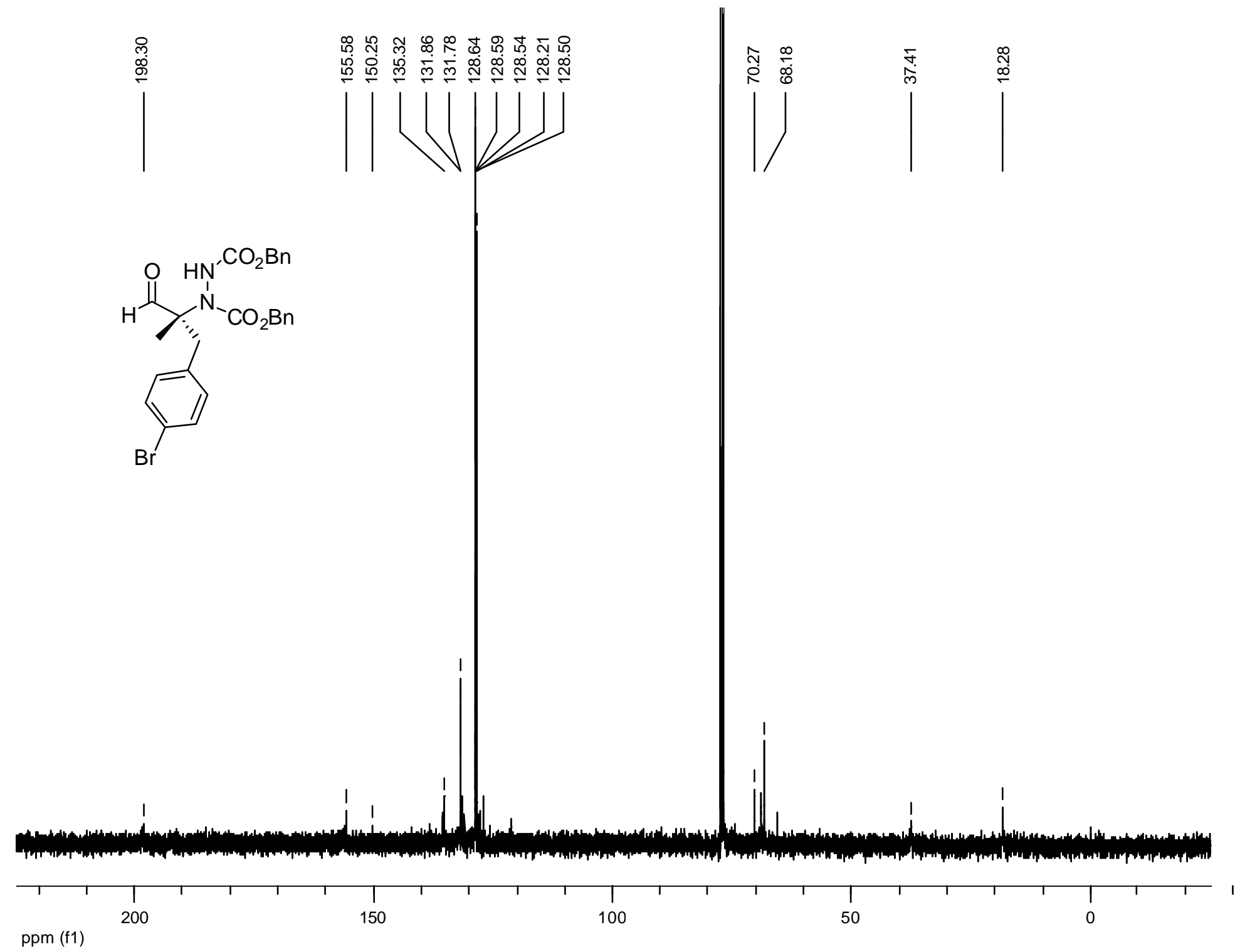




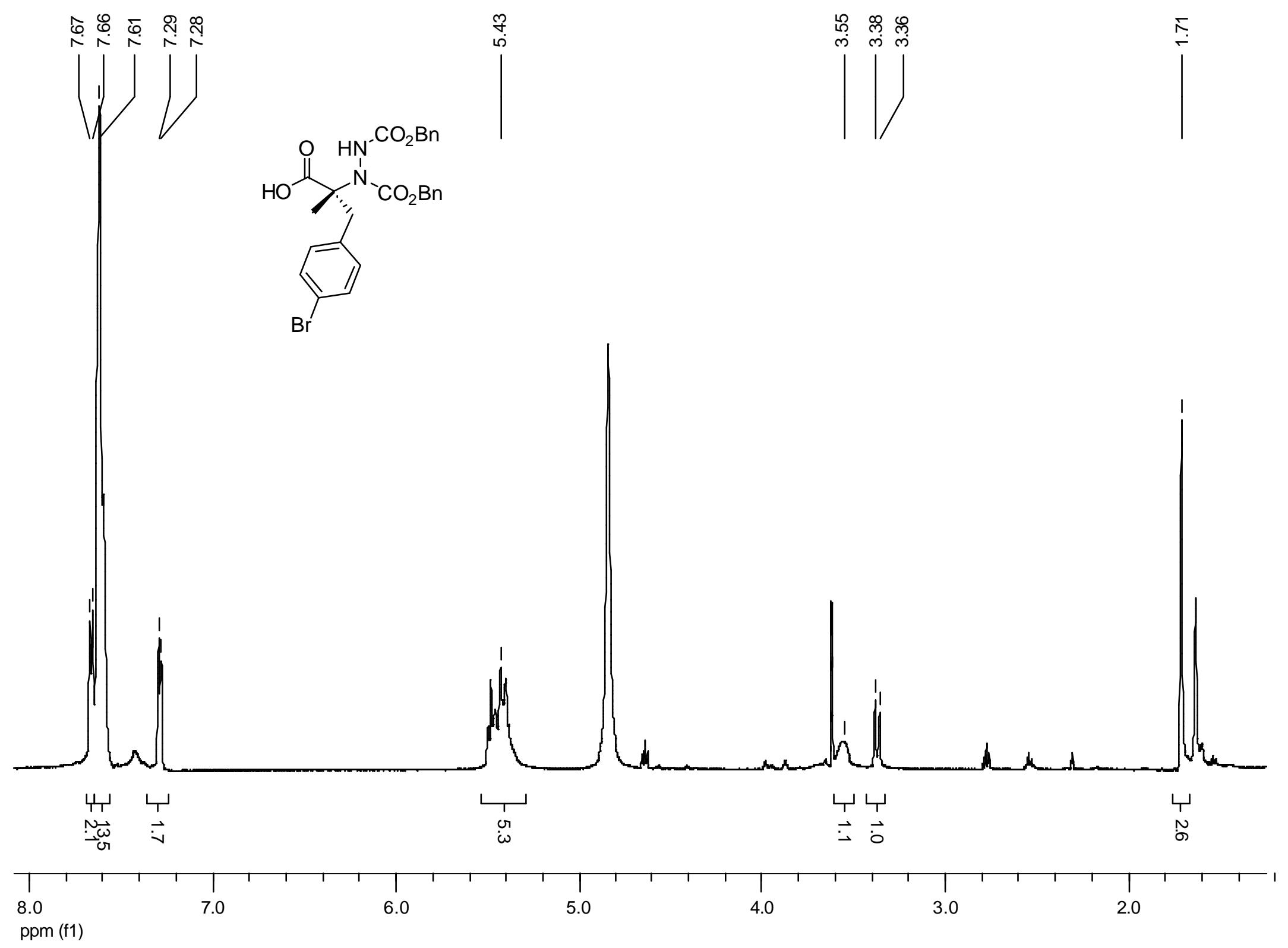




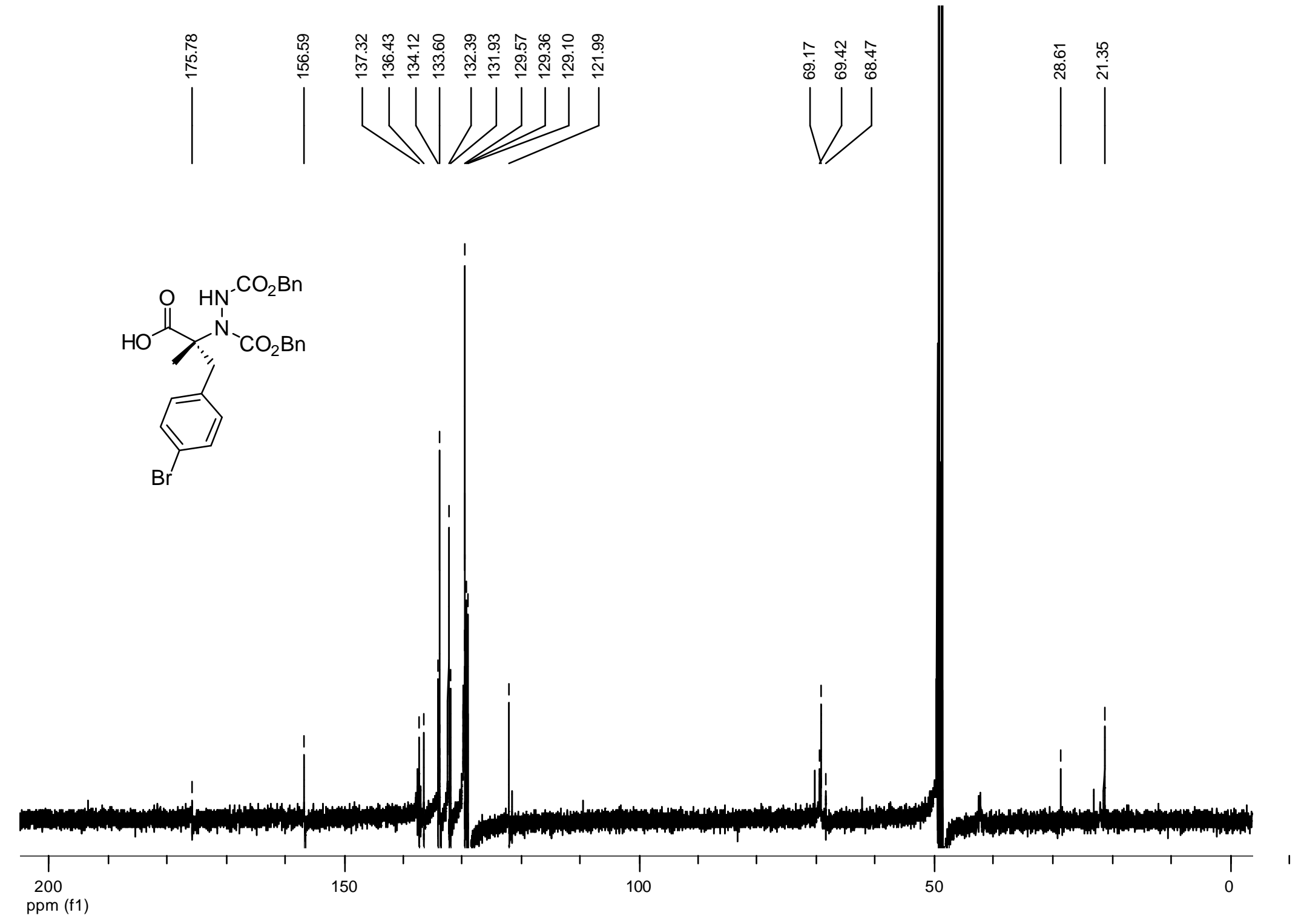




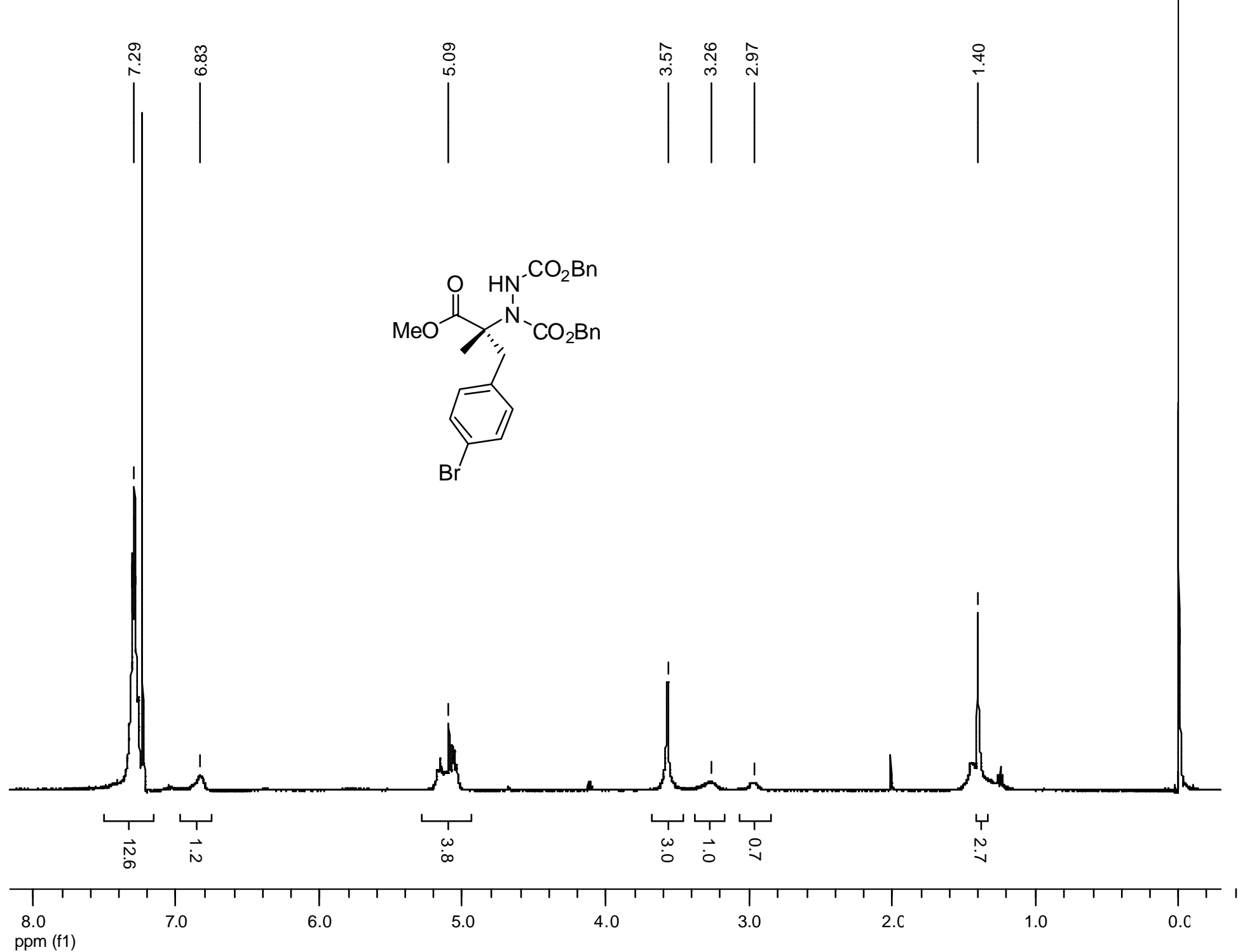




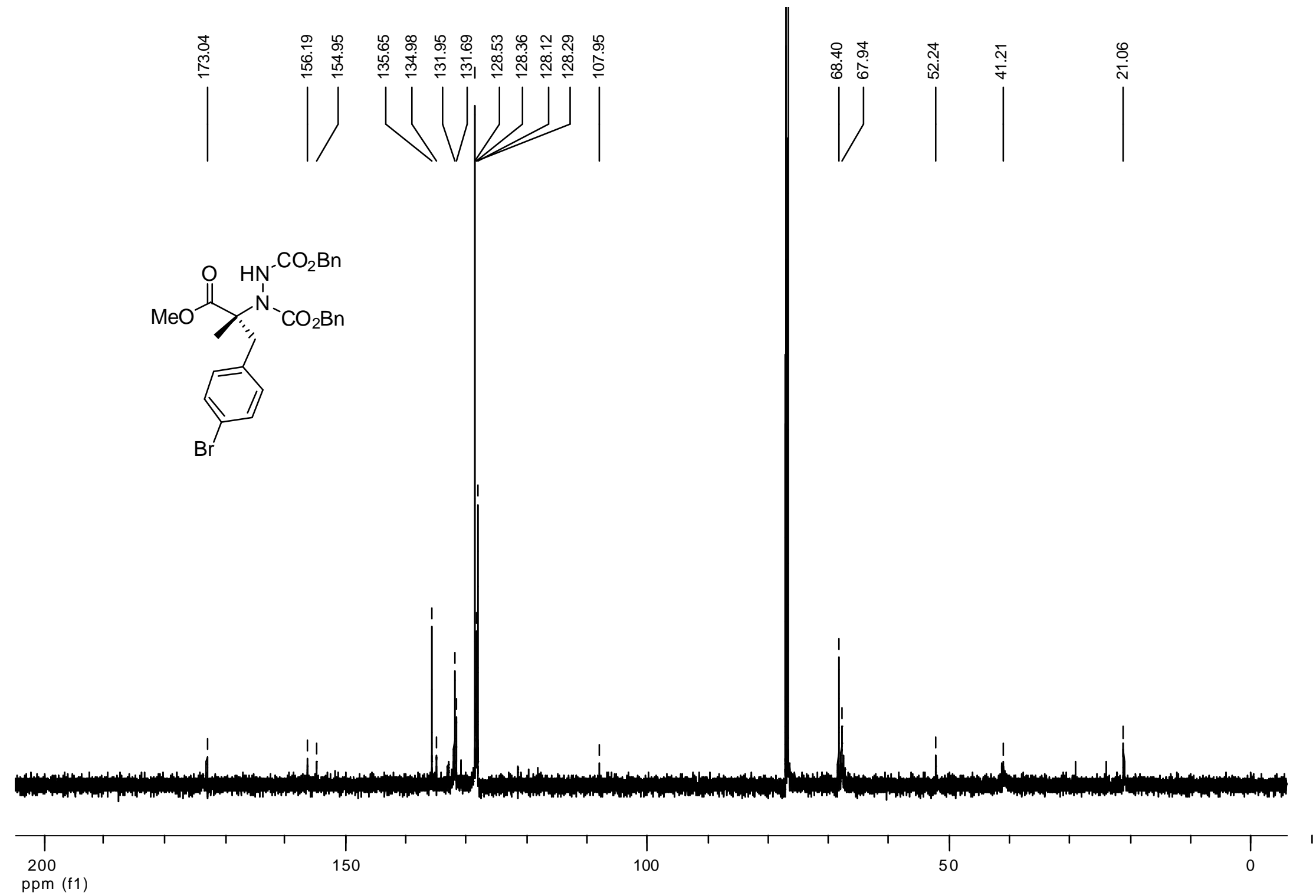



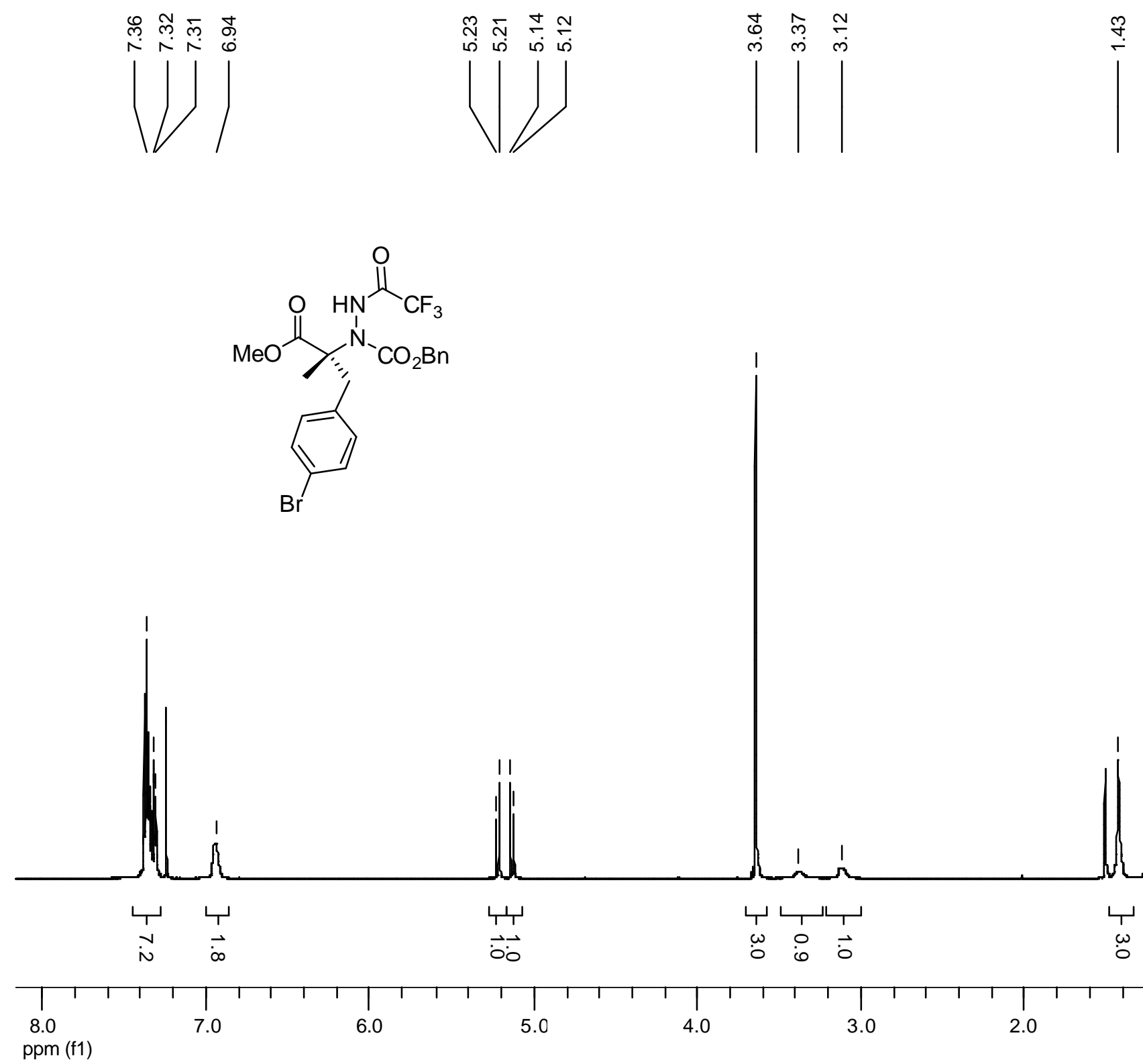

ppm (f1)
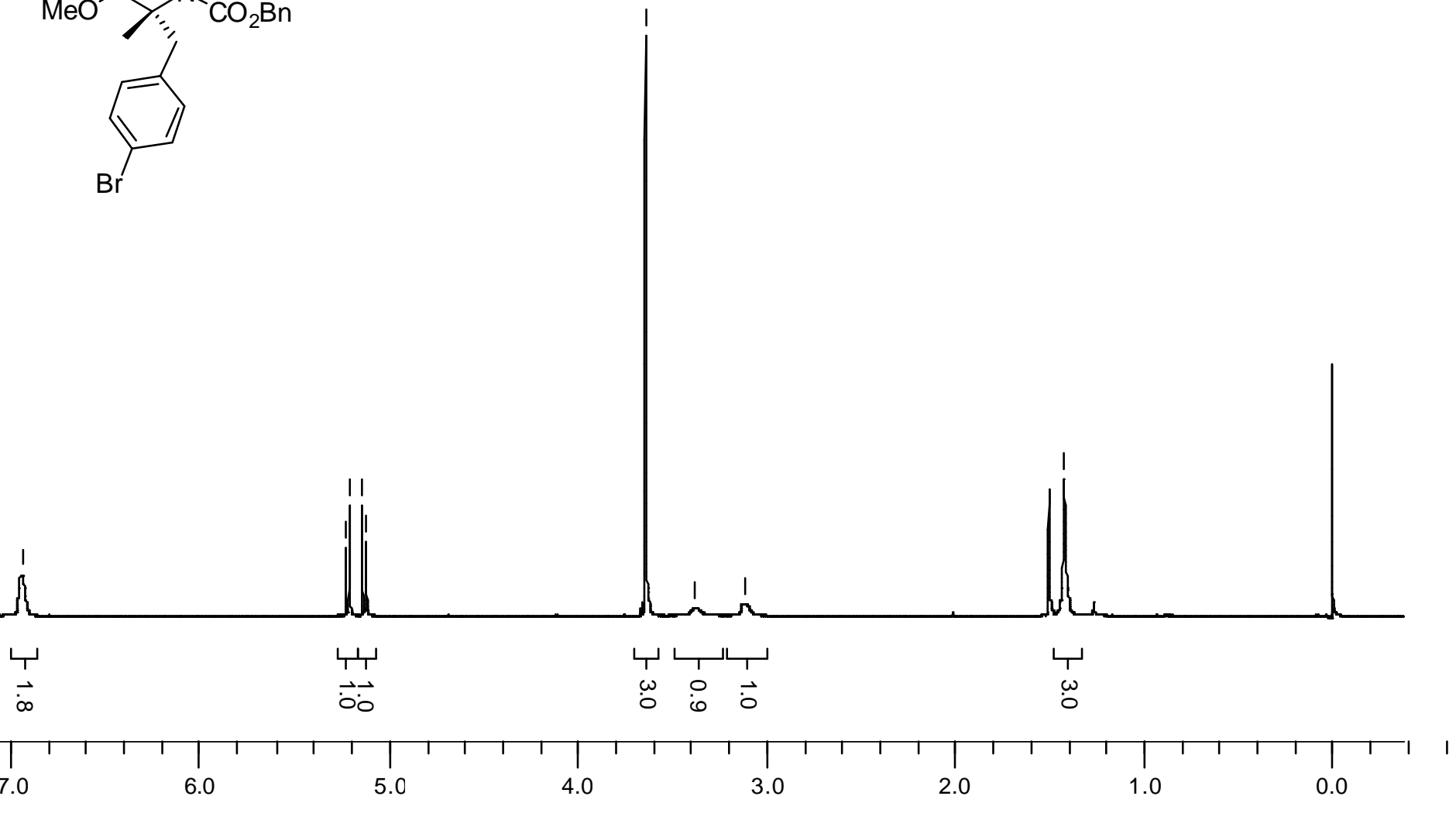


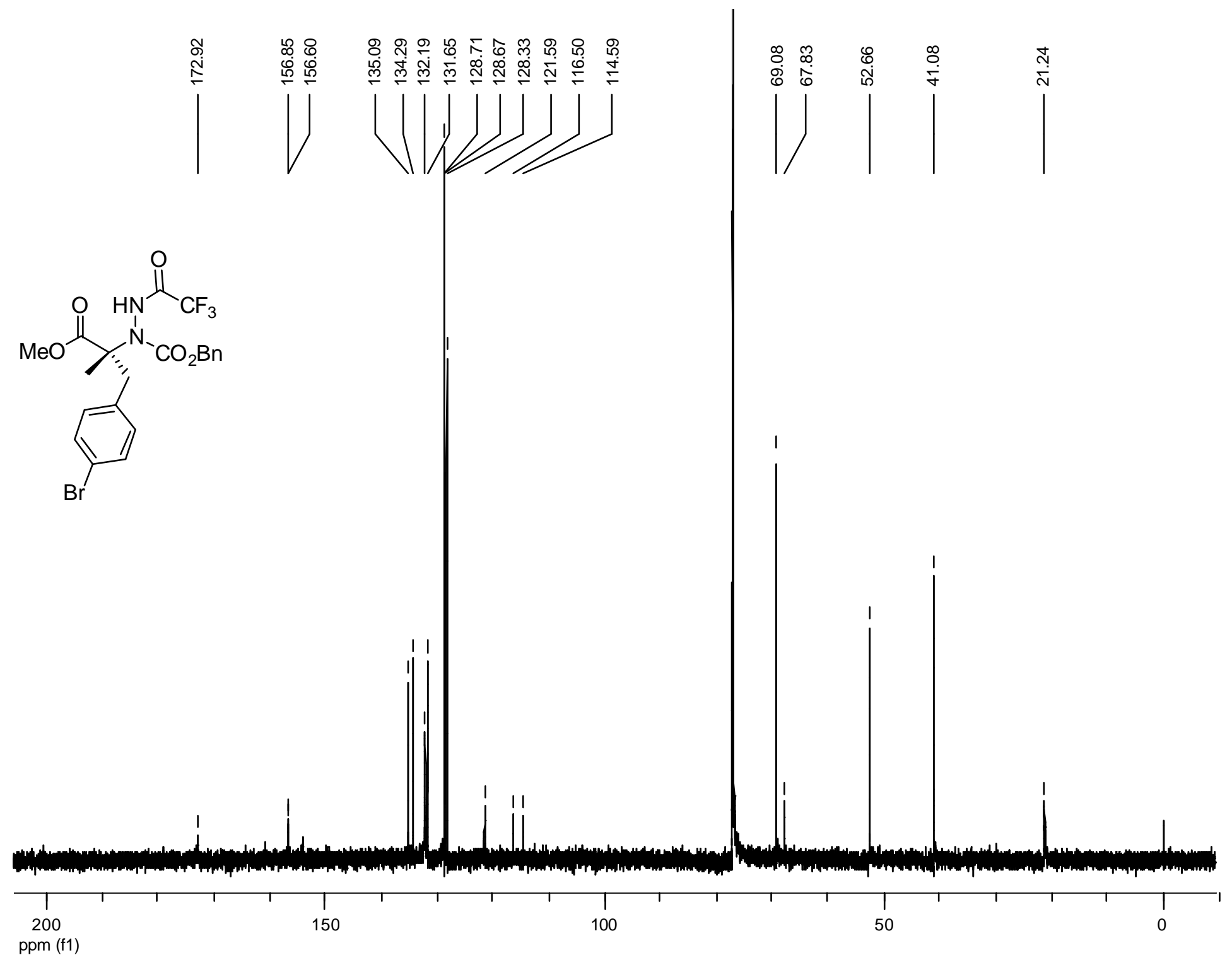




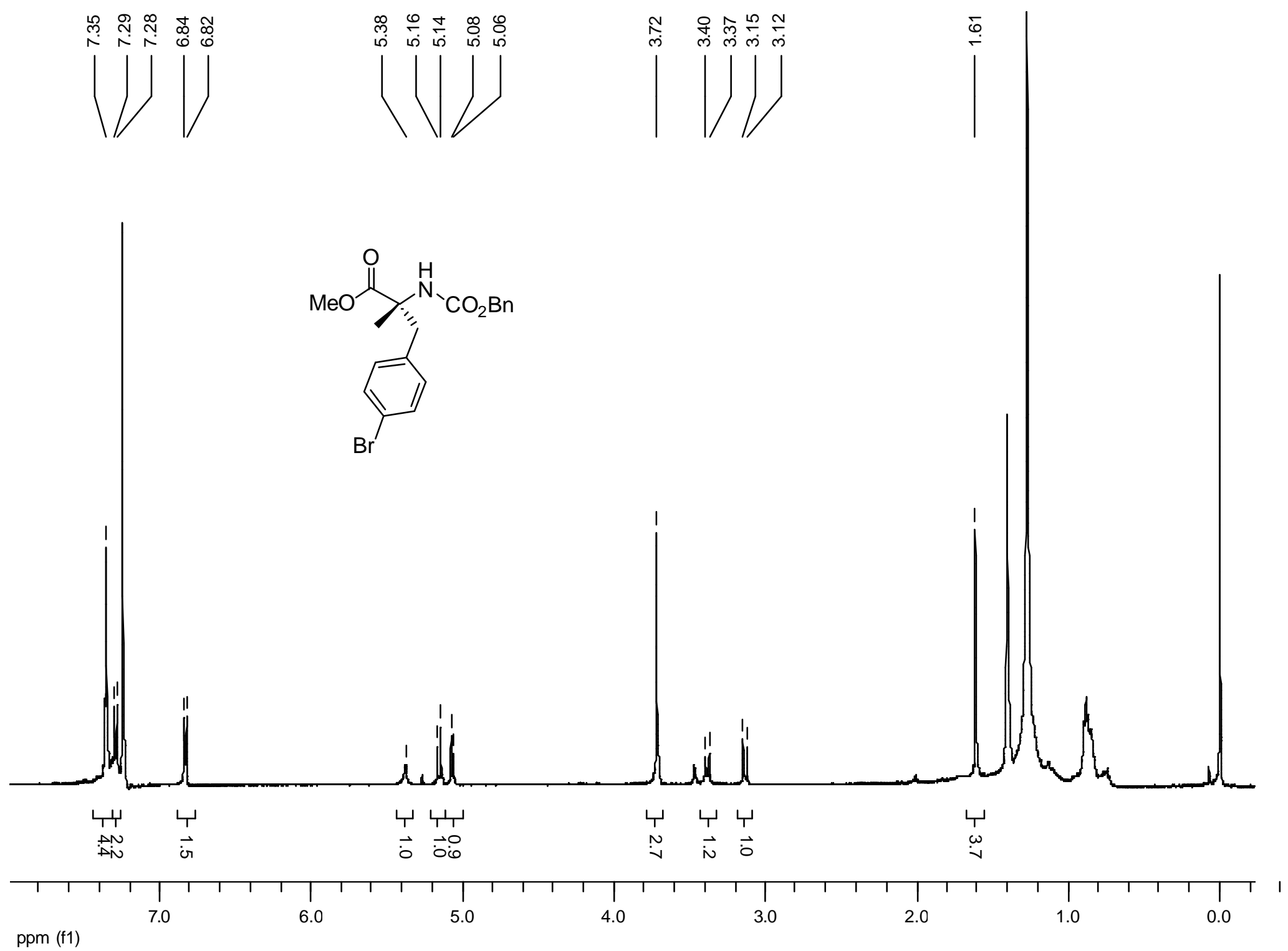



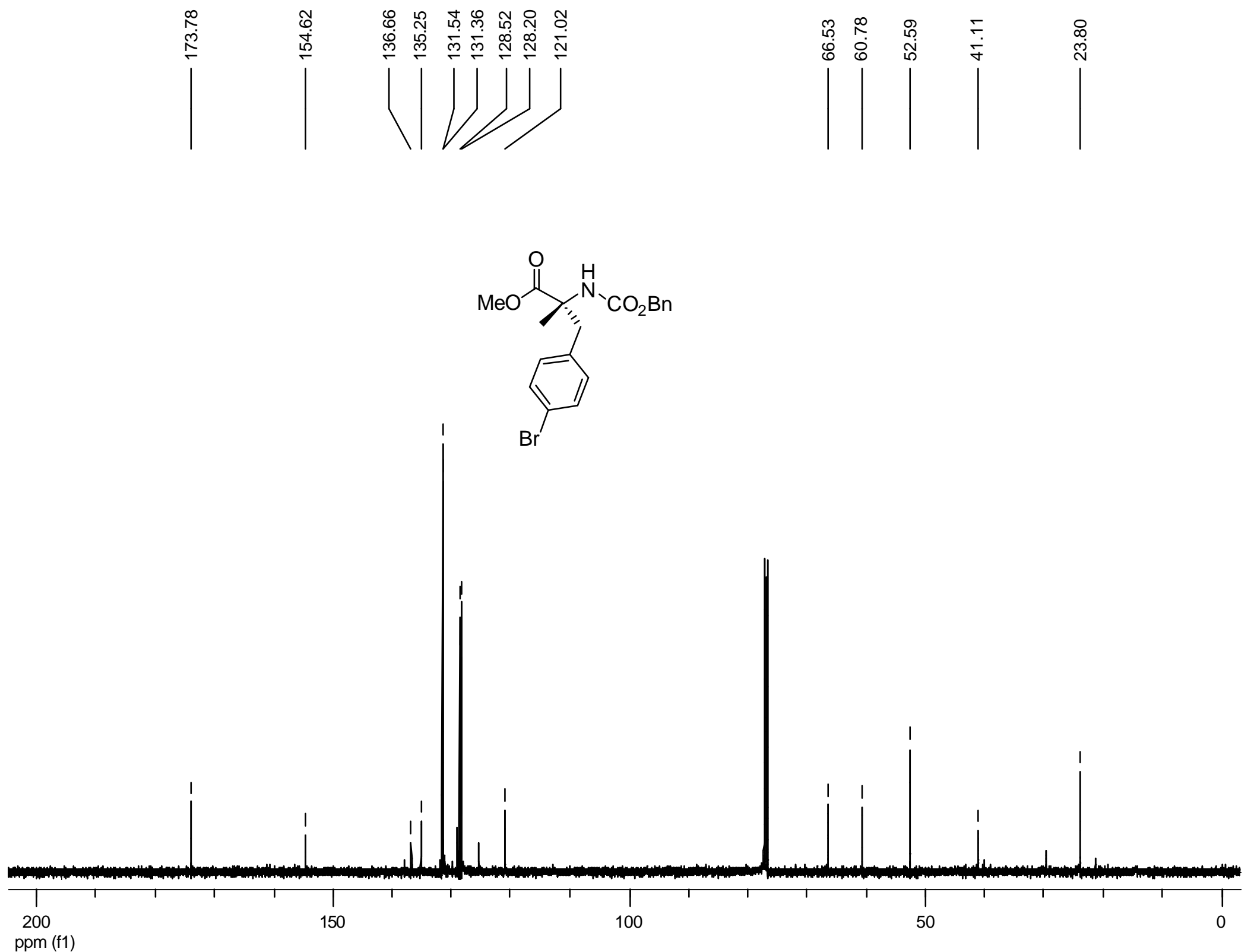

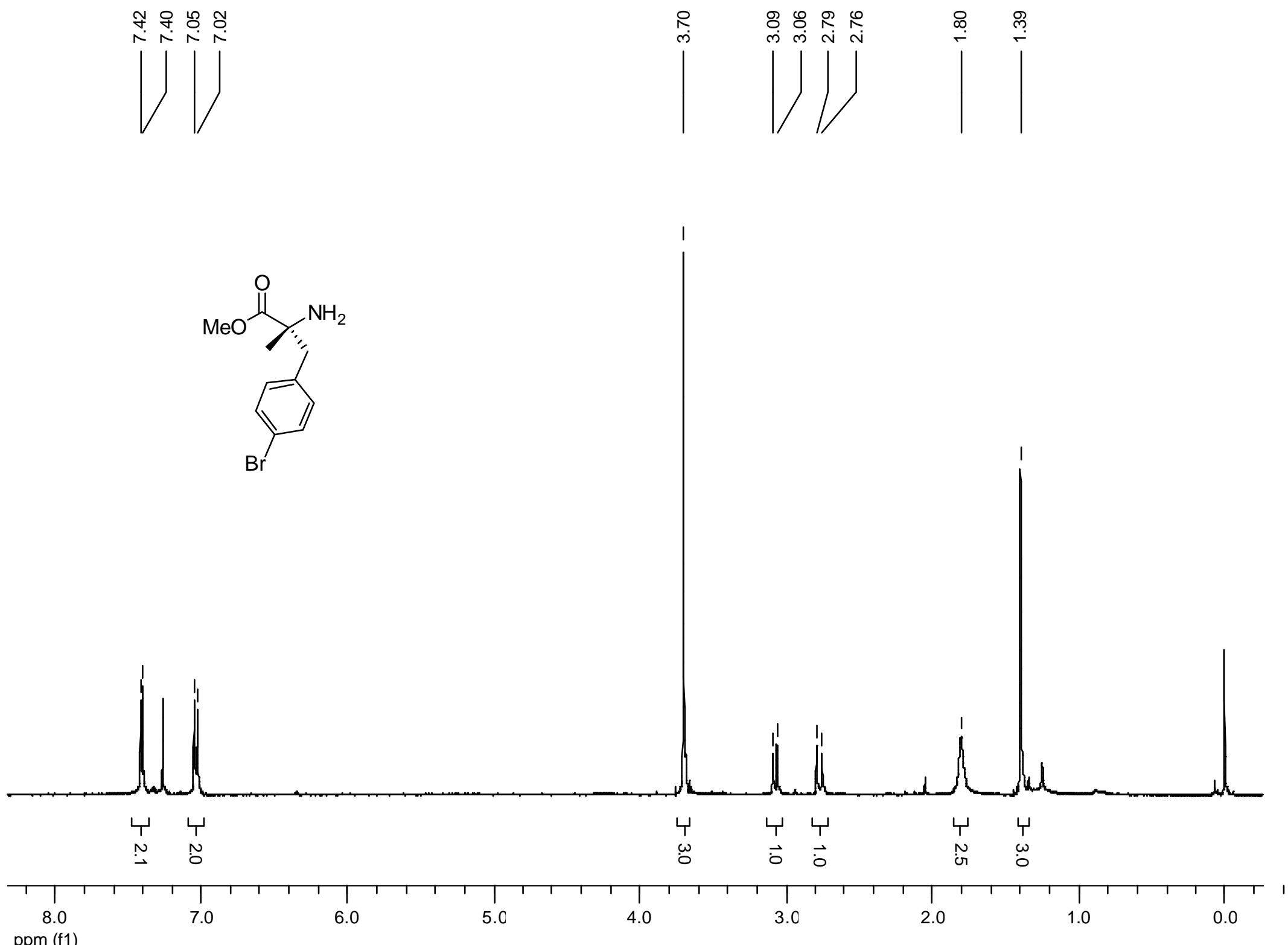


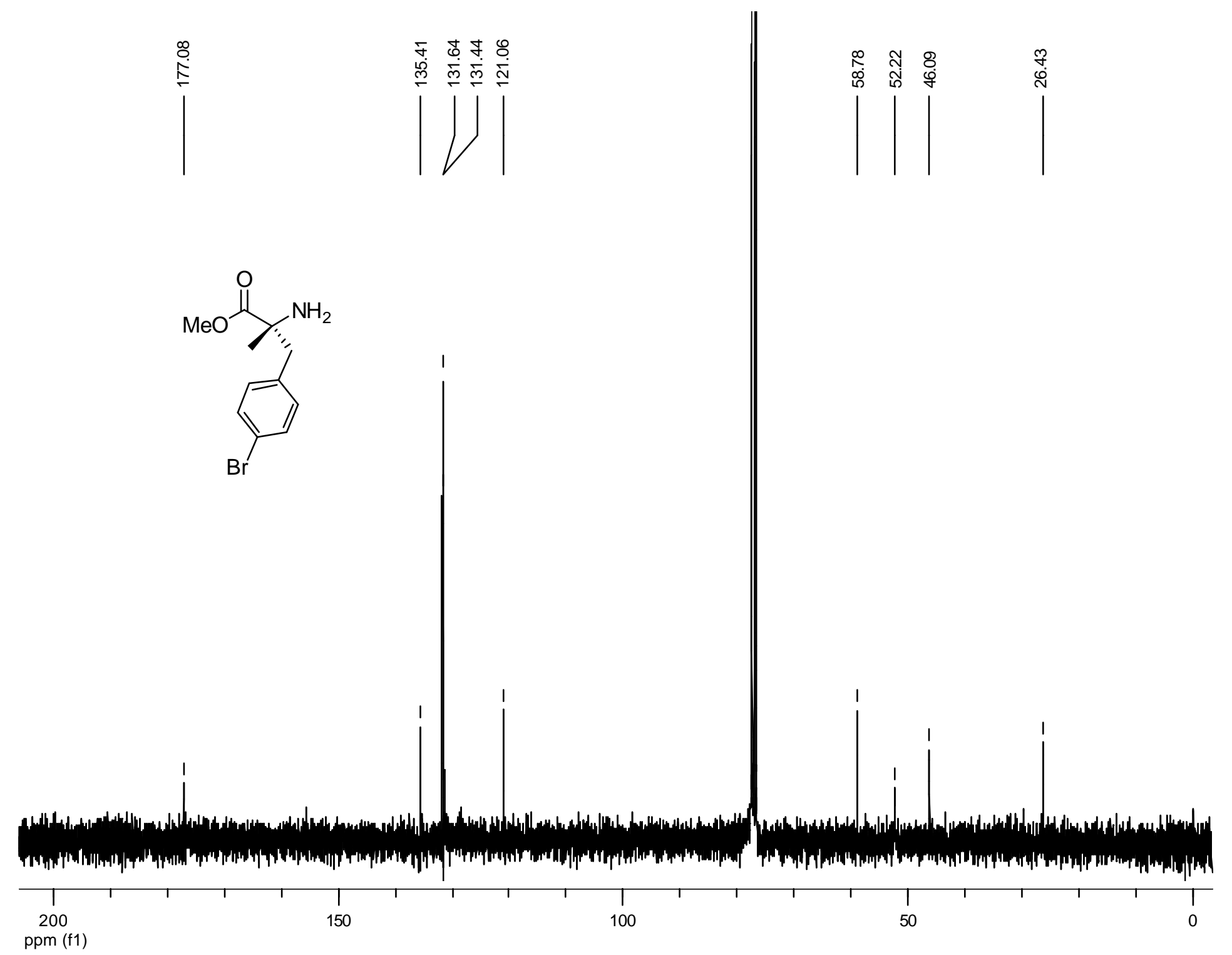



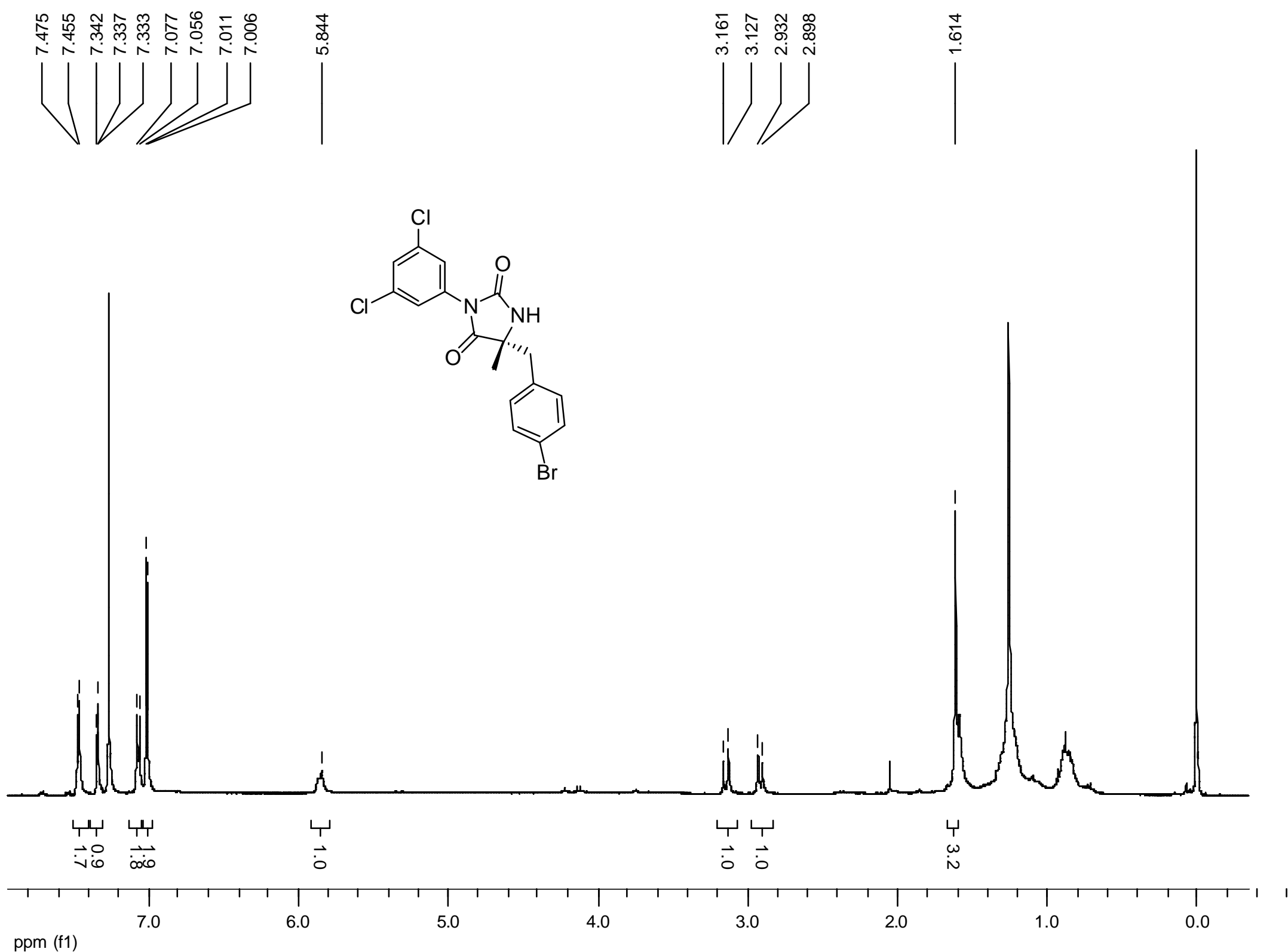


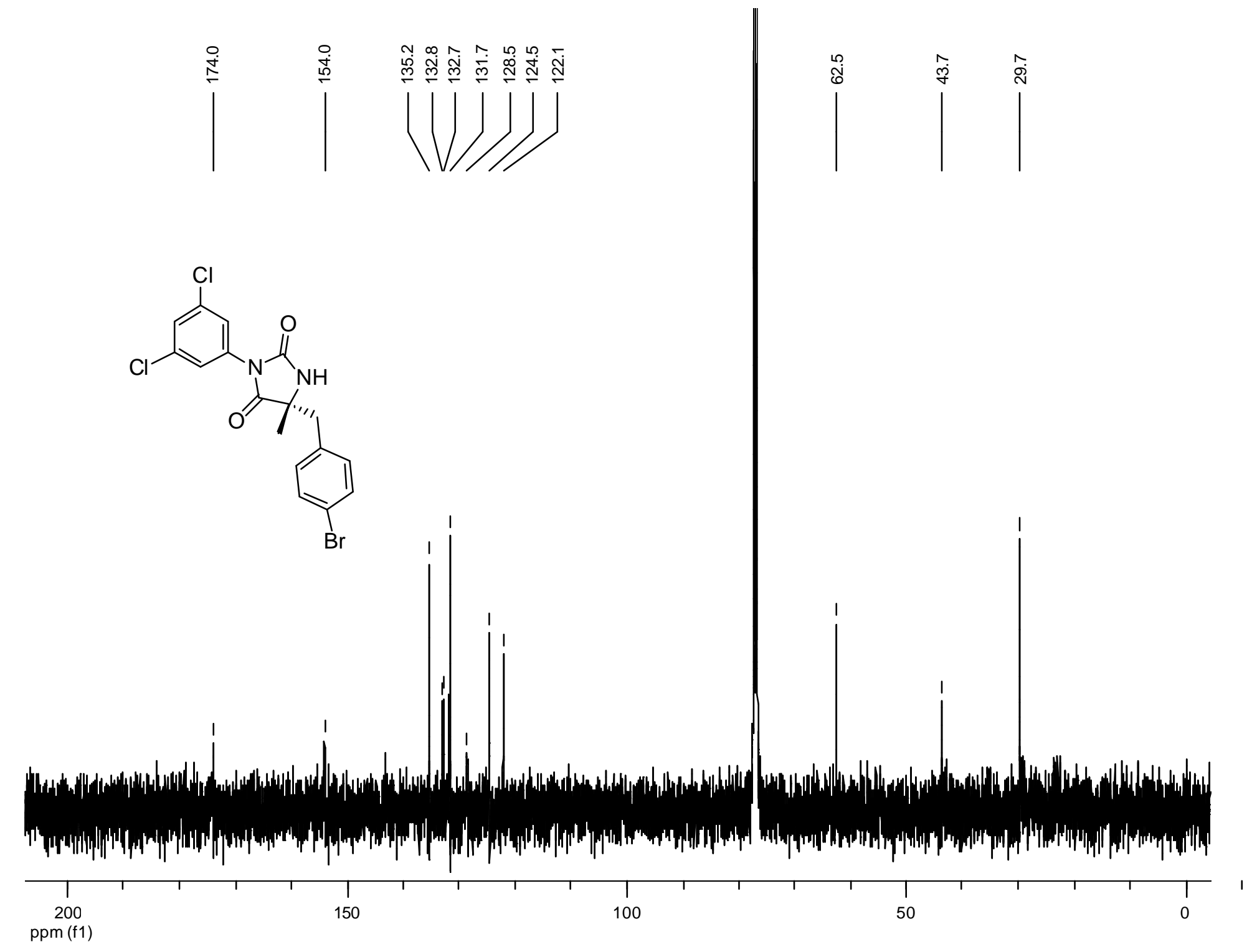




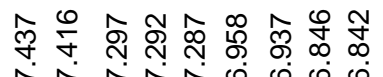

.

UWU
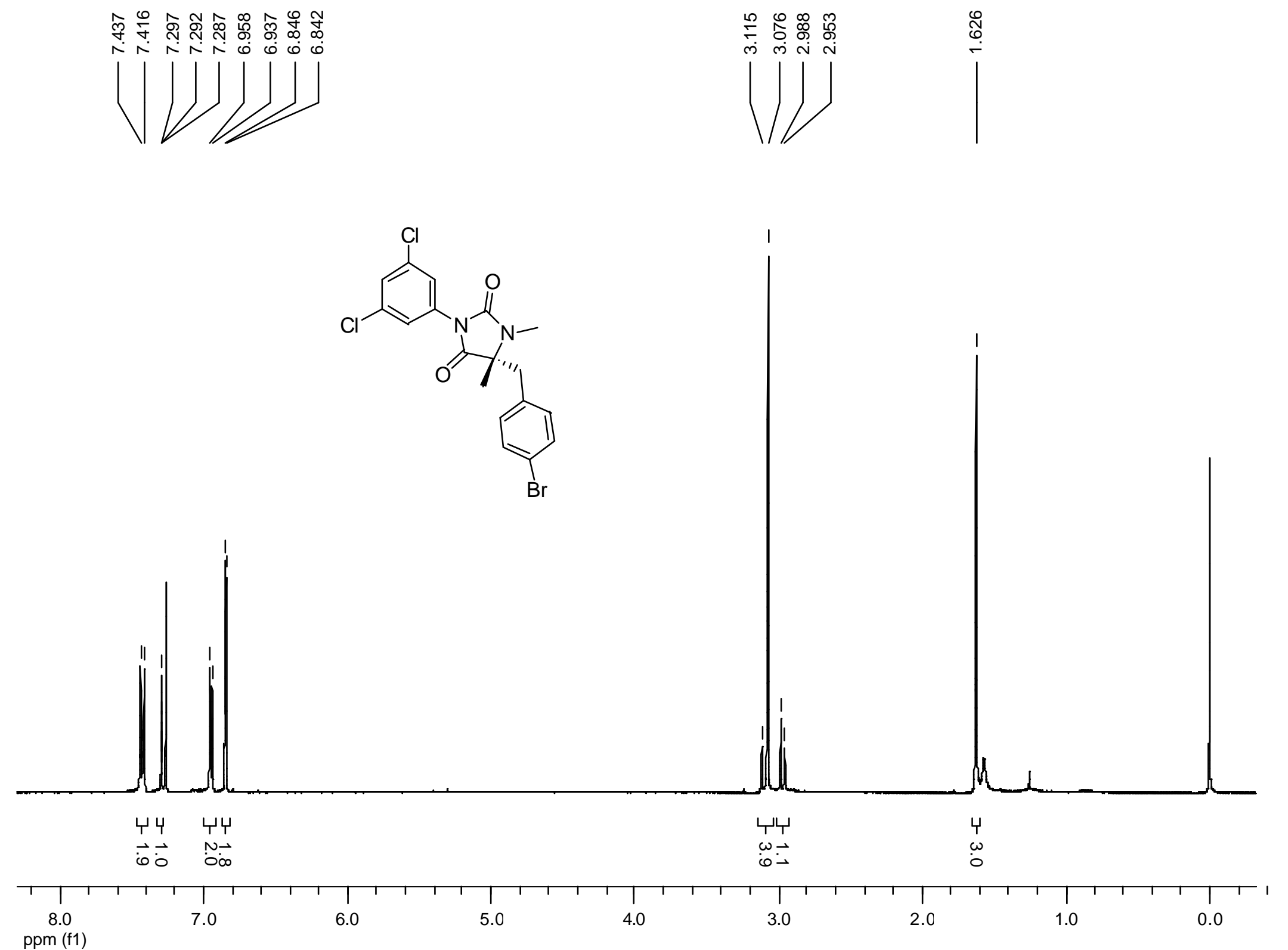

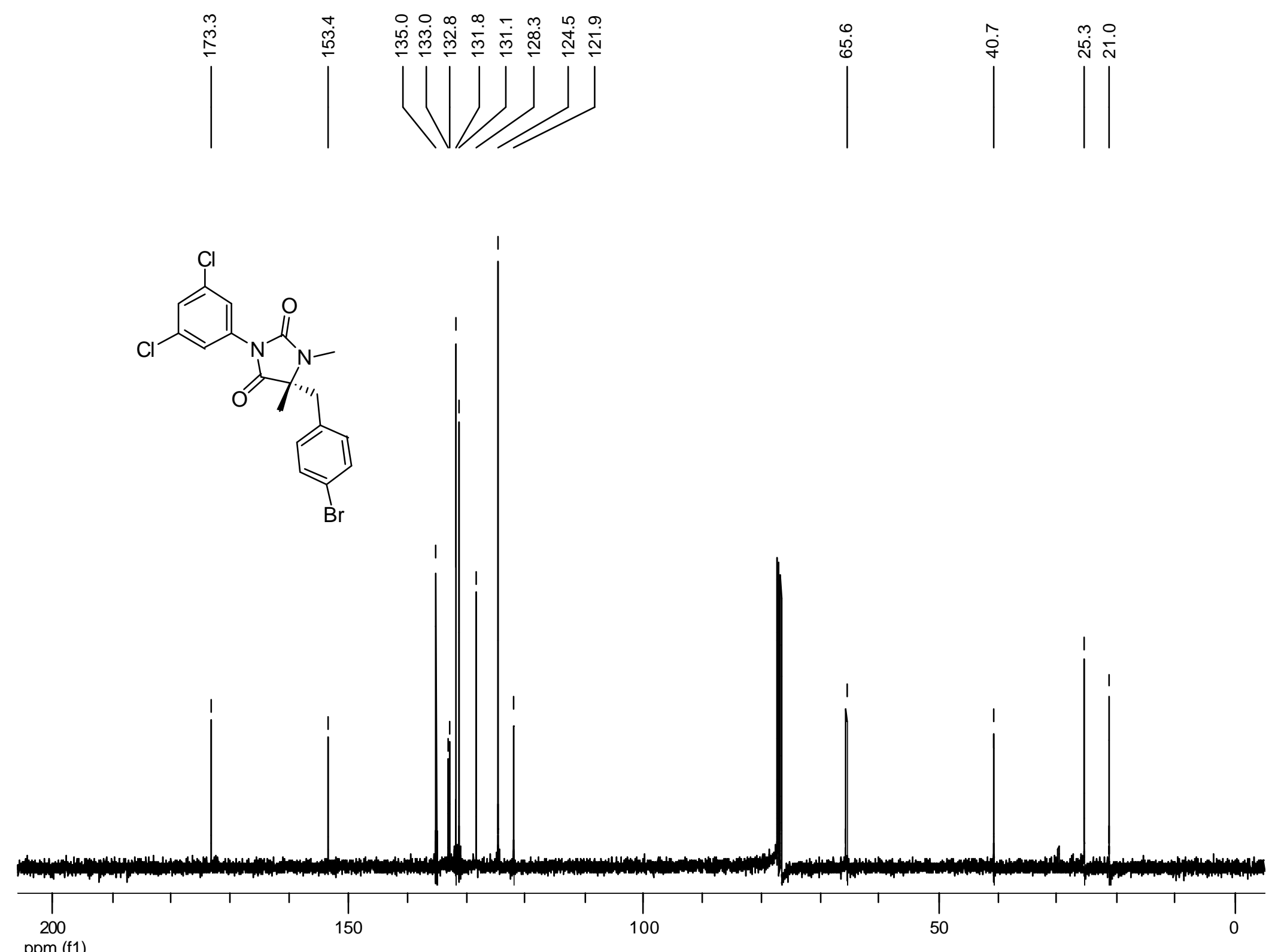